Удк 331.538:316.32-053.9

\title{
РЕАЛИЗАЦИЯ ПОТЕНЦИАЛА СТАРШЕГО ПОКОЛЕНИЯ. УЧАСТИЕ НА РЫНКЕ ТРУДА
}

\author{
Монастырный Евгений Александрович1,2,3, \\ e.monastyrny@gmail.com \\ Касинский Сергей Викторович 4 , \\ P70_mail@gks.ru \\ Дырко Нина Петровна4, \\ P70_mail@gks.ru \\ Котова Валентина Викторовна4, \\ P70_mail@gks.ru \\ Павлова Ирина Анатольевна $3,1,2$, \\ iapav@mail.ru \\ ${ }^{1}$ Национальный исследовательский Томский политехнический университет, \\ Россия, 634050, г. Томск, пр. Ленина, 30 \\ 2 Томский государственный университет систем управления и радиоэлектроники, \\ Россия, 634050, г. Томск, пр. Ленина, 40 \\ 3 Томский научный центр СО РАН, \\ Россия, 634055, г. Томск, пр. Академический, 10/4 \\ 4 Федеральная служба государственной статистики по Томской области, \\ Россия, 634050, г. Томск, ул. Гагарина, 56
}

\begin{abstract}
Монастырный Евгений Александрович, доктор экономических наук, профессор Школы инженерного предпринимательства Национального исследовательского Томского политехнического университета; профессор кафедры управления инновациями Томского государственного университета систем управления и радиоэлектроники; заведующий лабораторией устойчивого развития социально-экономических систем Томского научного центра СО РАН.
\end{abstract}

Касинский Сергей Викторович, руководитель территориального органа Федеральной службы государственной статистики по Томской области.

Дырко Нина Петровна, заместитель руководителя территориального органа Федеральной службы государственной статистики по Томской области.

Котова Валентина Викторовна, главный специалист-эксперт отдела сводных статистических работ территориального органа Федеральной службы государственной статистики по Томской области.

Павлова Ирина Анатольевна, кандидат экономических наук, старший научный сотрудник лаборатории устойчивого развития социально-экономических систем Томского научного центра СО PAН; доцент Школы инженерного предпринимательства Национального исследовательского Томского политехнического университета; доцент кафедры управления инновациями Томского государственного университета систем управления и радиоэлектроники.

Актуальность работы определяется глобальными процессами: старением населения в целом, вызванным снижением рождаемости и ростом продолжительности жизни; увеличением экономически активного возраста. Статистика рабочей силы в Российской Федерации традиционно рассматривается как статистика лиц трудоспособного возраста и лиц старше трудоспособного воз- 
раста. Детализация старших возрастных групп, как правило, ограничена. Это наблюдается и в специализированных официальных статистических сборниках, и в разделе "Старшее поколение» Федеральной службы государственной статистики. Причем по множеству показателей данных федеральной статистики в региональном разрезе нет в свободном доступе. Цель исследования определена в первой статье цикла и остается прежней - оценить характеристики выборки лиц старших возрастных групп и пенсионеров по старости по статистическим данным Росстата и Пенсионного фонда РФ по Томской области с позиций подготовки информации для принятия управленческих решений. Задачами работы являются исследование участия в рабочей силе пожилых людей и разработка модели процессов реализации трудового потенциала старшего поколения. Источники информации - Росстат, Единая межведомственная информационно-статистическая систем (ЕМИСС), Томскстат, информация, получаемая по согласованным запросам в территориальный орган статистики, результаты социологических исследований. Методы: используются подходы описательной статистики: сравнения, отношения, визуализация динамики изменений, статистический анализ. Логика, структура и методы анализа материала соответствуют принятым в официальных статистических обзорах и аналитических записках. При моделировании используются подходы «мягкого» системного анализа. Результаты. Проведен детальный анализ положения пенсионеров на рынке труда, распределения занятого населения разных возрастных групп по видам экономической деятельности, занятиям (должностям) и возрастным группам. По результатам анализа статистических данных сделаны выводы. В Томской области с 2010 по 2018 2. прослеживалась тенденция демографического старения населения. Одним из последствий увеличения доли пожилых людей является рост демографической нагрузки на население трудоспособного возраста. Это приводит к необходимости расширения рынка труда, главным образом занятости пенсионеров. Моделирование. Выбранное представление статистических данных позволило выделить три основных процесса, определяющих реализацию потенциала старшего поколения: процесс участия в трудовой силе; процесс выхода из трудовой деятельности; процесс смертности в каждой возрастной группе. Данные показывают, что в возрастной группе 70-74 численность работающих становится статистической погрешностью, а процесс выхода из трудовой деятельности фиксирует факт возможности реализации потенциала этой части людей старшего возраста только в социальной сфере. Для выделенных процессов проведена полиномиальная аппроксимация. Разработана модель-видение явления, включающая более широкие процессы, влияющие на реализацию потенциала старшего поколения: социальный, экономический, физиологический, а также процессы формализованной и неформализованной поддержки старшего поколения.

Ключевые слова: Реализация трудового потенциала, работающие пенсионеры, старшие возрастные группы, реформа пенсионной системы.

Настоящая работа завершает цикл статей, посвященных вопросам сбора и анализа статистической информации о процессах реализации потенциала старшего поколения в Российской Федерации на примере Томской области $[1,2]$. Актуальность проблемы определяется глобальными процессами: старением населения в целом, вызванным снижением рождаемости и ростом продолжительности жизни; увеличением экономически активного возраста.

Статистика рабочей силы в Российской Федерации традиционно рассматривается как статистика лиц трудоспособного возраста и лиц старше трудоспособного возраста. Детализация старших возрастных групп, как правило, ограничивается годами (55-59), (60-64), (65-72) или даже (55-59), (60-72). Это наблюдается и в специализированных официальных статистических сборниках [3] и в разделе «Старшее поколение» Федеральной службы государственной статистики [4]. В регионах России официальная статистика действует по федеральным правилам. Причем по множеству показателей данных федеральной статистики в региональном разрезе нет в свободном доступе.

Несколько облегчает ситуацию статистические наблюдения, по которым доступны микроданные. Это «Комплексное наблюдение условий жизни населения» (КОУЖ) и «Российский мониторинг экономического положения и здоровья населения» (RLMS) $[5,6]$. 
Недостатки российской статистики рабочей силы по старшим возрастным группам заставляют исследователей прибегать к комбинированным источникам информации, например в работе [7] используются данные статистики, результаты социологических опросов и интернет-исследований.

В рамках международных организаций анализ рабочей силы старшего возраста ведется более последовательно [8-10]. Возможность отслеживать долговременные изменения статистических данных по большому числу показателей во многих странах позволили выявить два периода изменений доли работников старшего возраста в трудовых ресурсах. До конца 90-х годов происходило сокращение этой доли. Очевидно, что сокращение доли пожилых работников в рабочей силе в основном связано с повышением уровня жизни населения и стимулами, заложенными в системах социального обеспечения [10]. В настоящее время преобладает тенденция увеличения этой доли [8], что связано с увеличением продолжительности активной жизни.

Цель настоящего исследования определена в первой статье цикла и остается прежней: оценить характеристики выборки лиц старших возрастных групп и пенсионеров по старости по статистическим данным Росстата и Пенсионного фонда РФ по Томской области с позиций подготовки информации для принятия управленческих решений.

Задачи, которые необходимо решить в рамках этой работы:

1. Исследовать уровень участия на рынке труда людей старших возрастных групп.

2. Разработать на основе анализа статистической информации модель процессов реализации потенциала старшего поколения.

\section{Методология}

В работе используются подходы описательной статистики: сравнения, отношения, визуализация динамики изменений, статистический анализ. Логика, структура и методы анализа материала соответствуют принятым в официальных статистических обзорах и аналитических записках. Такой подход наиболее удобен для представления больших объемов информации и привычен для лиц, использующих информацию для принятия управленческих решений.

Моделирование. Явление старения человечества и процесс жизнедеятельности людей старших возрастных групп как социально-экономические и психологофизиологические феномены развиваются в сложном слабоструктурированном проблемном поле и относятся к классу «мягких» систем, что требует от исследователей использования подходов «мягкого» системного анализа [11-13]. Множественность проблем, неочевидность методов их решения приводят к необходимости построения комплексной модели «мягких» систем как согласованной совокупности моделей разного уровня обобщения и различного целеполагания [14].

\section{Выбор основных источников информации}

Источниками информации являются Росстат [4, 15], Единая межведомственная информационно-статистическая систем (ЕМИСС) [16], Томскстат [17], аналитические записки Томскстата [18-20], информация, получаемая по согласованным запросам в территориальный орган статистики, результаты социологических исследований. Дополнительные источники информации приводятся в работе «Социальноэкономическая статистика благополучия старшего поколения» [21].

Исследование уровня участия на рынке труда людей старших возрастных групп проводилось с использованием информации следующих статистических форм: 
- Выборочное наблюдение доходов населения и участия в социальных программах. Вопросник для домохозяйства. Индивидуальный вопросник для лиц в возрасте 16 лет и более.

- Выборочное обследование рабочей силы. Анкета выборочного обследования рабочей силы.

- Выборочное обследование организаций (без предприятий, относящихся к субъектам малого предпринимательства и без организаций с численностью менее 15 человек) о средней начисленной заработной плате и численности работников по группам занятий, возрастным группам.

- Форма № 94 (ПЕНСИИ) «Сведения о численности пенсионеров и суммах назначенных им пенсий».

- Комплексное наблюдение условий жизни населения (КОУж).

\section{Участие на рынке труда}

О положении пенсионеров на рынке труда можно судить по данным о численности работающих пенсионеров, об их участии в составе рабочей силы, по показателям занятости и безработицы.

В 2010-2018 гг. в динамике численности работающих пенсионеров можно выделить два периода - период роста и период снижения.

С 2010 по 2015 г. численность работающих пенсионеров неуклонно росла. На 1 января 2016 г. насчитывалось 119,5 тыс. работающих пенсионеров, что составляло $47,5 \%$ от их общего числа (рис. 1 ).

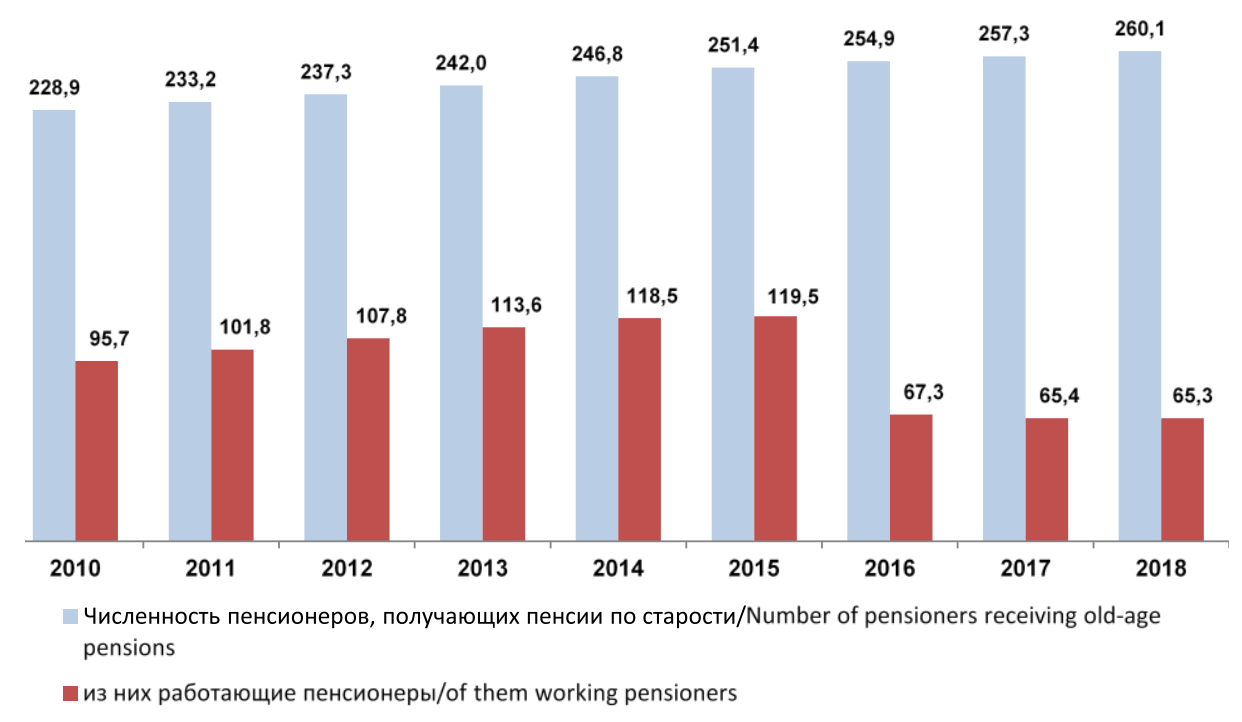

Pис. 1. Численность пенсионеров, получающих пенсии по старости, из них работающие пенсионеры, на 1 января года, следующего за отчетным, тыс. чел.

Fig. 1. Number of pensioners receiving old-age pensions, including working pensioners, as of January 1 of the year following the reporting year, thousand people

В последующие годы численность работающих пенсионеров снижалась. В январе 2017 г. снижение численности работающих пенсионеров (в 1,8 раза) по сравнению с 1 января 2016 г. обусловлено вступлением в силу Федерального закона от 29.12.2015 № 385-Ф3 «О приостановлении действия отдельных положений законодательных актов Российской Федерации, внесении изменений в отдельные законодательные акты Рос- 
сийской Федерации и особенностях увеличения страховой пенсии, фиксированной выплаты к страховой пенсии и социальных пенсий», предусматривающего неиндексацию пенсий работающим пенсионерам.

На 1 января 2019 г. в Томской области работало 65,3 тыс. пенсионеров $(25,1 \%)$. При этом пятую часть работающих $(21,4 \%)$ составляли пенсионеры, получающие досрочную трудовую пенсию (женщины в возрасте до 54 лет включительно, мужчины в возрасте до 59 лет включительно).

Активность старшего поколения на рынке труда заметно снизилась - сократилось их присутствие в составе рабочей силы, уменьшился уровень занятости.

Доля лиц старше трудоспособного возраста (мужчины в возрасте 60-72 лет; женщины в возрасте 55-72 лет) в составе рабочей силы Томской области в 2018 г. составила $6,6 \%$, в 2010 г. $-8,2 \%$.

Из общего количества занятых в экономике женщин женщины в возрасте 55-72 года составили в 2018 г. 10,8 \% (в 2010 г. - 12,1\%), мужчины в возрасте 60-72 лет - 3,2 \% (в 2010 г. - 5,1\%) из общей численности занятых в экономике лиц мужского пола.

Учитывая гендерные различия населения пенсионного возраста, можно отметить, что в общей численности рабочей силы населения в возрасте старше трудоспособного женщин 76,0 \%, мужчин - 24,0\%.

Уровень занятости населения в возрасте старше трудоспособного снизился с $32,5 \%$ в 2010 г. до 19,9\% в 2018 г. В то же время отметим, что уровень занятости всего населения, а именно населения в возрасте 15-72 лет увеличился с 60,8 \% в 2010 г. до $62,4 \%$ в 2018 г.

Уровень занятости женщин старшего возраста снизился с 38,1 \% в 2010 г. до 21,8 \% в 2018 г., мужчин - с 24,0 до 15,6 \%. Уровень занятости женщин постоянно превышал уровень занятости мужчин.

Наиболее предпочтительные виды деятельности, сосредоточившие наибольшее число населения в возрасте старше трудоспособного, - это образование и промышленность. В 2018 г. первое место по числу занятых занимала сфера образования, здесь трудился каждый четвертый пенсионер (24,5 \% от численности занятых в возрасте старше трудоспособного). На втором месте - промышленное производство, сосредоточившее $17,8 \%$ от числа всех занятых в возрасте старше трудоспособного. На третьем месте торговля $-11,8 \%$, далее деятельность в области здравоохранения и предоставления социальных услуг $-10,7 \%$.

Распределение по видам деятельности занятого населения трудоспособного возраста несколько иное: на первом месте промышленное производство $(23,1 \%)$, на втором - торговля $(17,3 \%)$, на третьем - образование (10,1\%) (рис. 2$)$.

Распределение работников по занятиям, по данным выборочного обследования средней заработной платы работников крупных и средних организаций по профессиям и должностям, показало, что в октябре 2017 г. наибольшее число $(29,1 \%)$ занятых в возрасте 55 лет и более сосредоточено на местах специалистов высшего уровня квалификации.

Более половины $(51,2 \%)$ из числа работников старшего возраста были заняты на местах руководителей организаций и их структурных подразделений (служб), специалистов высшего и среднего уровня квалификации, требующих достаточно высокого уровня образования.

Вместе с тем из числа занятых пенсионеров 16,8 \% трудились на рабочих местах неквалифицированного труда, 14,6 \% - операторами, аппаратчиками, машинистами установок и машин (табл. 1). 


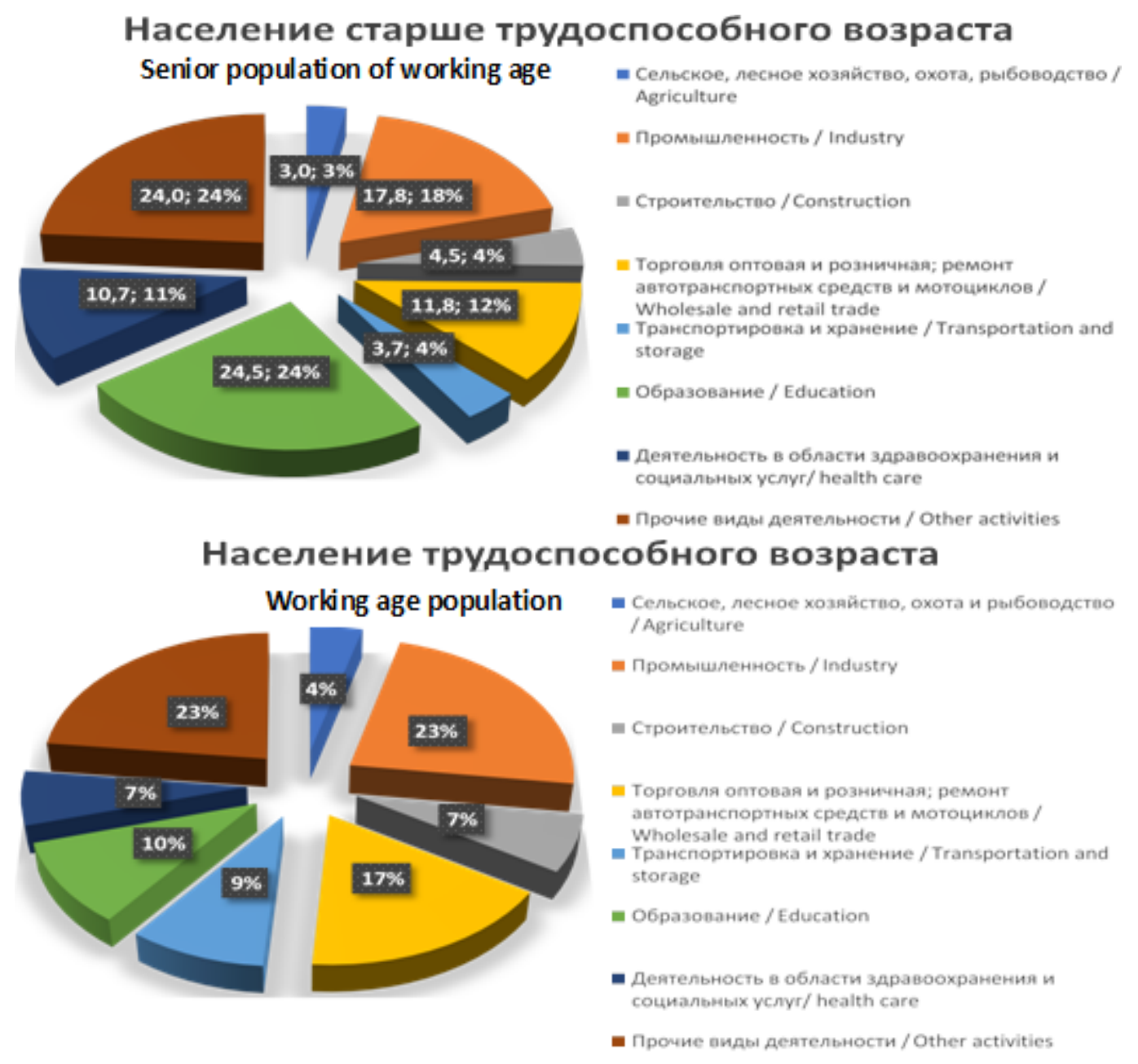

Puc. 2. Распределение занятого населения разных возрастных групп по видам экономической деятельности в 2018 г., в \%

Fig. 2. Distribution of employed population of different age groups by types of economic activity in 2018, in \%

Самая высокая концентрация работников старшего возраста отмечалась среди неквалифицированных рабочих, в октябре 2017 г. - 35,2 \%, т. е. каждый третий неквалифицированный рабочий в возрасте 55 лет и более. На втором месте - специалисты среднего уровня квалификации (27,2 \%). Много лиц старшего возраста среди руководителей организаций и их структурных подразделений (служб) и среди служащих, занятых подготовкой информации, оформлением документации, учетом и обслуживанием. Причем в сравнении с 2011 г. представительство лиц старшего возраста во всех группах занятий выросло, за исключением служащих, занятых подготовкой информации, оформлением документации, учетом и обслуживанием, а также работников сферы обслуживания, жилищно-коммунального хозяйства, торговли и родственных видов деятельности (рис. 3).

Население старших возрастов, как правило, получало заработную плату ниже по сравнению со средним значением по всем группам занятий. Менее ощутимой разница в оплате труда складывалась у руководителей организаций и их структурных подразделений (служб), а также у специалистов высшей квалификации. Более ощутимой разница была у работников сферы обслуживания, жилищно-коммунального хозяйства, тор- 
говли и родственных видов деятельности, а также у операторов, аппаратчиков, машинистов установок и машин. Причем тенденция, чем старше возраст, тем ниже оплата труда, наблюдалась довольно часто и была характерна для квалифицированных рабочих промышленных предприятий, работников сферы обслуживания, операторов, аппаратчиков, машинистов установок и машин и неквалифицированных рабочих (табл. 2).

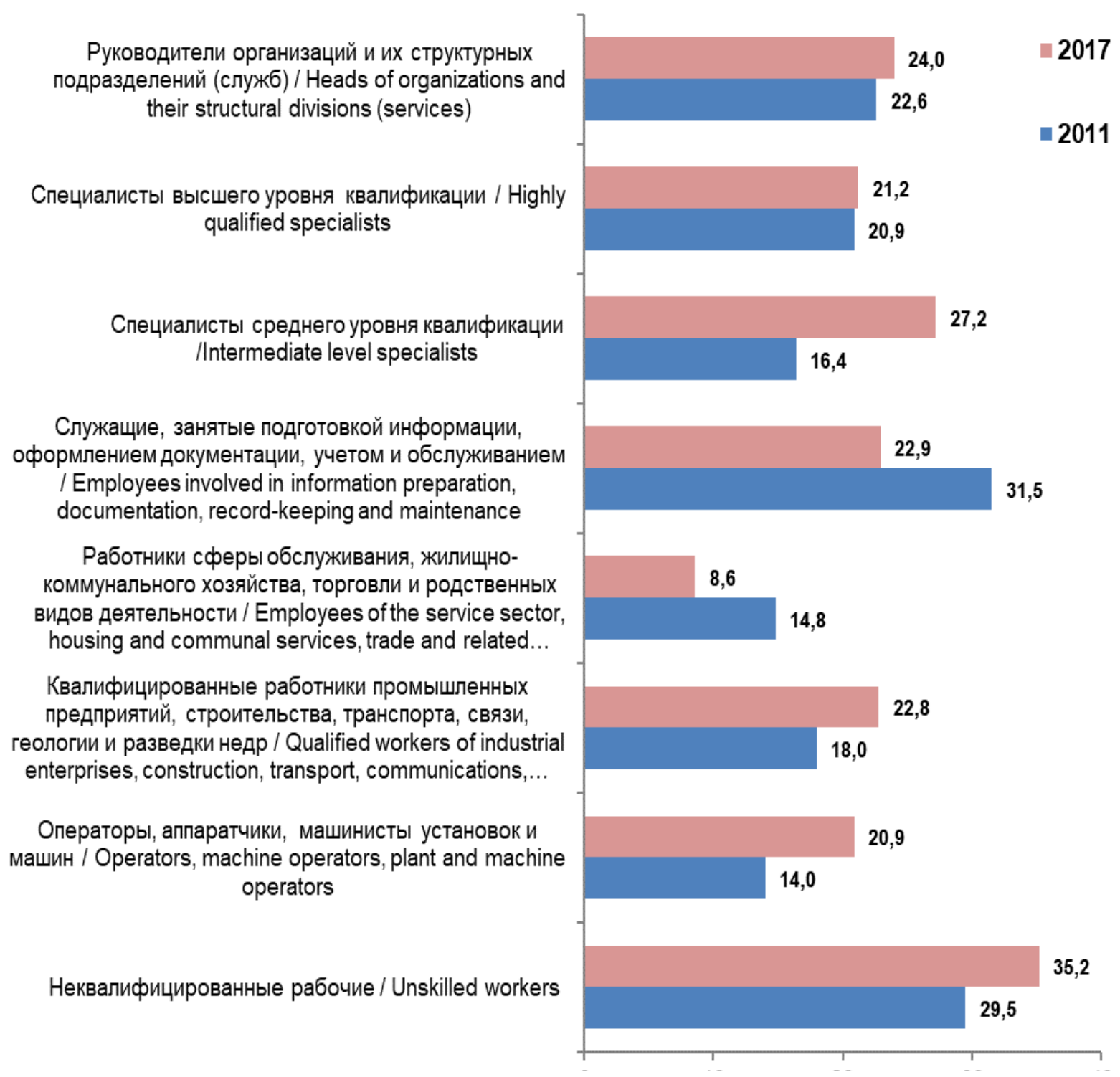

Рис. 3. Доля населения в возрасте 55 лет и более в общей численности работников по занятиям, в \%

Fig. 3. Share of population aged 55 years and over in the total number of employees by occupation, in percentage

Несмотря на то, что на рынке труда уменьшился сегмент, представленный старшим поколением, он обладает некоторым потенциалом к адаптации на конкурентном рынке труда, о чем свидетельствует уменьшение доли безработных в общей численности рабочей силы старшей возрастной группы. Уровень безработицы среди населения в возрасте старше трудоспособного снизился с 2,9 \% в 2010 г. до 1,5 \% в 2018 г. В возрастной категории 15-72 года уровень общей безработицы, снизился в этот период с 7,7 до 6,3 \%. 
таблица 1. Распределение работников по занятиям в возрасте 55 лет и более (по данным выборочного обследования крупных и средних организаций), в \% к итогу Table 1. Distribution of employees by occupation at the age of 55 years and more (based on a sample survey of large and medium-sized organizations) as a percentage of total

\begin{tabular}{|c|c|c|}
\hline & \multicolumn{2}{|c|}{$\begin{array}{l}\text { Октябрь } \\
\text { October }\end{array}$} \\
\hline & 2011 & 2017 \\
\hline Все работники/All employees & 100 & 100 \\
\hline $\begin{array}{l}\text { Руководители организаций и их структурных подразделений (служб) } \\
\text { Heads of organizations and their structural divisions (services) }\end{array}$ & 12,7 & 10,4 \\
\hline $\begin{array}{l}\text { Специалисты высшего уровня квалификации } \\
\text { Highly qualified specialists }\end{array}$ & 28,8 & 29,1 \\
\hline $\begin{array}{l}\text { Специалисты среднего уровня квалификации } \\
\text { Intermediate level specialists }\end{array}$ & 10,0 & 11,8 \\
\hline $\begin{array}{l}\text { Служащие, занятые подготовкой информации, оформлением документации, учетом и } \\
\text { обслуживанием } \\
\text { Employees involved in information preparation, documentation, record-keeping and maintenance }\end{array}$ & 5,4 & 2,0 \\
\hline $\begin{array}{l}\text { Работники сферы обслуживания, жилищно-коммунального хозяйства, торговли и родст- } \\
\text { венных видов деятельности } \\
\text { Employees of the service sector, housing and communal services, trade and related activities }\end{array}$ & 3,7 & 3,3 \\
\hline $\begin{array}{l}\text { Квалифицированные работники сельского, лесного, охотничьего хозяйств, рыбоводства и } \\
\text { рыболовства } \\
\text { Skilled workers in agriculture, forestry, hunting, fish farming and fishing }\end{array}$ & 12,4 & 0,5 \\
\hline $\begin{array}{l}\text { Квалифицированные работники промышленных предприятий, строительства, транспорта, } \\
\text { связи, геологии и разведки недр } \\
\text { Qualified workers of industrial enterprises, construction, transport, communications, geology } \\
\text { and subsoil exploration }\end{array}$ & - & 11,5 \\
\hline $\begin{array}{l}\text { Oператоры, аппаратчики, машинисты установок и машин } \\
\text { Operators, machine operators, plant and machine operators }\end{array}$ & 9,9 & 14,6 \\
\hline $\begin{array}{l}\text { Неквалифицированные рабочие } \\
\text { Unskilled workers }\end{array}$ & 17,3 & 16,8 \\
\hline
\end{tabular}

Снижение занятости населения в возрасте старше трудоспособного было характерно и для субъектов Сибирского федерального округа. Уровень занятости старшего поколения снизился в 2018 г. в сравнении с 2016 г. во всех субъектах СФО, за исключением Республики Тыва. В 2018 г. наибольший уровень занятости сложился в Омской области - 33,4 \%, наименьший - в Томской области (табл. 3 ).

Уровень безработицы снизился в половине субъектах СФО, а в другой - напротив вырос. В 2018 г. самый высокий уровень безработицы среди старшего поколения сложился в Республике Тыва, низкий - в Томской области.

В Томской области с 2010 по 2018 г. прослеживалась тенденция демографического старения населения, которая проявилась в росте численности населения старших возрастов. Одним из последствий увеличения доли пожилых людей, является рост демографической нагрузки на трудоспособное население трудоспособного возраста. Это приводит к необходимости расширения рынка труда, главным образом занятости пенсионеров.

Население старшего возраста продолжает трудовую деятельность и является участником рынка труда. Активность людей в старших возрастных группах обусловлена преимущественно причинами социально-экономического характера. К доминирующим следует отнести недостаток денежных средств, о чем свидетельствуют показатели замещения заработной платы пенсиями и величиной прожиточного минимума. 
Таблица 2. Средняя заработная плата работников по занятиям и возрастным группам за октябрь 2017 г., руб.

Table 2. Average salary of employees by occupation and age group for October 2017, RUB

\begin{tabular}{|c|c|c|c|c|c|c|c|}
\hline & \multirow[t]{2}{*}{$\begin{array}{l}\text { Средняя заработ- } \\
\text { ная плата по всем } \\
\text { возрастам - } \\
\text { всего, p. } \\
\text { Average salary by } \\
\text { all ages - total, } \\
\text { rubles }\end{array}$} & \multicolumn{3}{|c|}{$\begin{array}{c}\text { В том числе по } \\
\text { возрастным } \\
\text { группам, лет } \\
\text { Including age-related } \\
\text { groups, years }\end{array}$} & \multicolumn{3}{|c|}{$\begin{array}{c}\text { Отношение заработ- } \\
\text { ной платы по возрас- } \\
\text { тным группам к сред- } \\
\text { нему значению, \% } \\
\text { Ratio of wages by age } \\
\text { group to average value, \% }\end{array}$} \\
\hline & & $55-59$ & $60-64$ & $65+$ & $55-59$ & $60-64$ & $65+$ \\
\hline $\begin{array}{l}\text { Руководители организаций и их } \\
\text { структурных } \\
\text { подразделений (служб) } \\
\text { Managers of organizations and their } \\
\text { structural units (services) }\end{array}$ & 64623 & 59643 & 54503 & 58058 & 92,3 & 84,3 & 89,8 \\
\hline $\begin{array}{l}\text { Специалисты высшего уровня ква- } \\
\text { лификации } \\
\text { Highly qualified specialists }\end{array}$ & 38663 & 35656 & 32008 & 37303 & 92,2 & 82,8 & 96,5 \\
\hline $\begin{array}{l}\text { Специалисты среднего уровня } \\
\text { квалификации Intermediate level } \\
\text { specialists }\end{array}$ & 35602 & 35502 & 23519 & 26394 & 99,7 & 66,1 & 74,1 \\
\hline $\begin{array}{l}\text { Служащие, занятые подготовкой } \\
\text { информации, оформлением доку- } \\
\text { ментации, учетом и обслуживани- } \\
\text { ем } \\
\text { Employees involved in information } \\
\text { preparation, documentation, record- } \\
\text { keeping and maintenance }\end{array}$ & 20103 & 16286 & 15605 & 18569 & 81,0 & 77,6 & 92,4 \\
\hline $\begin{array}{l}\text { Работники сферы обслуживания, } \\
\text { жилищно-коммунального хозяйст- } \\
\text { ва, торговли и родственных видов } \\
\text { деятельности Employees of the } \\
\text { service sector, housing and } \\
\text { communal services, trade and related } \\
\text { activities }\end{array}$ & 23388 & 22634 & 16248 & 13390 & 96,8 & 69,5 & 57,3 \\
\hline $\begin{array}{l}\text { Квалифицированные работники } \\
\text { сельского, лесного, охотничьего } \\
\text { хозяйств, рыбоводства и рыболов- } \\
\text { ства } \\
\text { Skilled workers in agriculture, forest- } \\
\text { ry, hunting, fish farming and fishing }\end{array}$ & 22917 & 15097 & 28469 & 12330 & 65,9 & 124,2 & 53,8 \\
\hline $\begin{array}{l}\text { Квалифицированные работники } \\
\text { промышленных предприятий, } \\
\text { строительства, транспорта, связи, } \\
\text { геологии и разведки недр Qualified } \\
\text { workers of industrial enterprises, } \\
\text { construction, transport and communi- } \\
\text { cation, } \\
\text { geology and subsoil exploration }\end{array}$ & 37746 & 35052 & 33239 & 28308 & 92,9 & 88,1 & 75,0 \\
\hline $\begin{array}{l}\text { Операторы, аппаратчики, машини- } \\
\text { сты установок и машин } \\
\text { Operators, machine operators, plant } \\
\text { and machine operators }\end{array}$ & 39287 & 34636 & 32035 & 27311 & 88,2 & 81,5 & 69,5 \\
\hline $\begin{array}{l}\text { Неквалифицированные } \\
\text { рабочие } \\
\text { Unskilled laborers }\end{array}$ & 18055 & 18660 & 15063 & 14207 & 103,4 & 83,4 & 78,7 \\
\hline
\end{tabular}


Таблица 3. Показатели, характеризующие занятость населения в возрасте старше трудоспособного ${ }^{1}$, по субъектам Сибирского федерального округа

Table 3. Indicators characterizing employment of the population older than the working age ${ }^{1}$, on the subjects of the Siberian Federal District

\begin{tabular}{|c|c|c|c|c|c|c|}
\hline & \multicolumn{2}{|c|}{2016} & \multicolumn{2}{|c|}{2017} & \multicolumn{2}{|c|}{2018} \\
\hline & \begin{tabular}{|c|} 
Уровень \\
занятости, \\
Employment \\
rate \% \\
\end{tabular} & $\begin{array}{c}\text { Уровень безра- } \\
\text { ботицы, } \\
\text { Unemployment } \\
\text { rate \% } \\
\end{array}$ & \begin{tabular}{|c|} 
Уровень \\
занятости, \\
Employment \\
rate \% \\
\end{tabular} & \begin{tabular}{|c|} 
Уровень безра- \\
ботицы, \\
Unemployment \\
rate \% \\
\end{tabular} & \begin{tabular}{|c|} 
Уровень \\
занятости, \\
Employment \\
rate \% \\
\end{tabular} & $\begin{array}{l}\text { Уровень безра- } \\
\text { ботицы, } \\
\text { Unemployment } \\
\text { rate \% } \\
\end{array}$ \\
\hline $\begin{array}{l}\text { В среднем по } \\
\text { РФ } \\
\text { Average in } \\
\text { Russia }\end{array}$ & 29,8 & 3,1 & 28,8 & 3,3 & 29,0 & 2,8 \\
\hline $\begin{array}{l}\text { Республика } \\
\text { Алтай } \\
\text { Republic of } \\
\text { Altai }\end{array}$ & 30,6 & 3,3 & 32,4 & 4,4 & 25,4 & 4,4 \\
\hline $\begin{array}{l}\text { Республика } \\
\text { Тыва } \\
\text { Republic of } \\
\text { Tuva }\end{array}$ & 24,3 & 6,1 & 23,8 & 9,9 & 29,4 & 9,0 \\
\hline $\begin{array}{l}\text { Республика } \\
\text { Хакасия } \\
\text { Republic of } \\
\text { Khakassia } \\
\end{array}$ & 26,6 & 3,5 & 26,2 & 3,8 & 24,4 & 4,9 \\
\hline $\begin{array}{l}\text { Алтайский } \\
\text { край } \\
\text { Altai Region }\end{array}$ & 23,8 & 5,0 & 19,2 & 7,6 & 22,6 & 3,1 \\
\hline $\begin{array}{l}\text { Красноярский } \\
\text { край } \\
\text { Krasnoyarsk } \\
\text { region }\end{array}$ & 26,7 & 4,3 & 26,5 & 4,3 & 23,2 & 6,0 \\
\hline $\begin{array}{l}\text { Иркутская } \\
\text { область } \\
\text { Irkutsk region }\end{array}$ & 32,5 & 6,9 & 29,7 & 6,0 & 27,7 & 5,6 \\
\hline $\begin{array}{l}\text { Кемеровская } \\
\text { область Keme- } \\
\text { rovo region }\end{array}$ & 26,0 & 6,6 & 24,0 & 5,2 & 22,5 & 6,2 \\
\hline $\begin{array}{l}\text { Новосибир- } \\
\text { ская область } \\
\text { Novosibirsk } \\
\text { Region }\end{array}$ & 31,3 & 3,4 & 28,1 & 2,8 & 27,5 & 2,3 \\
\hline $\begin{array}{l}\text { Омская } \\
\text { область } \\
\text { Omsk region }\end{array}$ & 34,8 & 4,3 & 33,9 & 7,5 & 33,4 & 7,5 \\
\hline $\begin{array}{l}\text { Томская } \\
\text { область } \\
\text { Tomsk region }\end{array}$ & 23,9 & 1,5 & 22,2 & 3,8 & 19,9 & 1,5 \\
\hline
\end{tabular}

${ }^{1}$ Мужчины в возрасте 60-72 лет; женщины в возрасте 55-72 лет.

${ }^{1}$ Men aged 60-72 years; women aged $55-72$ years.

За исследуемый период старшее поколение снизило свое присутствие на рынке труда, что обусловлено, на наш взгляд, экономическими и институциональными факторами, среди которых изменения пенсионного обеспечения. 
В то же время реформирование пенсионной системы, заключающееся в постепенном повышении пенсионного возраста, неизменно приведет к увеличению участия людей старших возрастных групп на рынке труда. Значимость старшего поколения в экономическом развитии региона будет расти, что обусловливает необходимость создания благоприятных условий для реализации его ресурсного потенциала, а также изменение социокультурной парадигмы «старости», создающей представление о пожилых людях как о непроизводительной части общества.

\section{Моделирование исследуемого явления}

Результаты статистического анализа позволили поставить задачу математической аппроксимации эмпирических данных и разработки комплексной модели явления.

Несмотря на то, что возможны расхождения из-за разных методик сбора информации, значительный интерес представляет сравнительный анализ данных, полученных из разных статистических источников. На рис. 4 приведены данные о численности, смертности, занятости населения старших возрастных групп Томской области. Демографические оценки для старших возрастных групп проводились на основе итогов последней переписи населения и текущего учета демографических событий, форма статистического наблюдения № 1-У, занятость оценивалась по итогам выборочного обследования рабочей силы. Были выделены возрастные группы (50-54, 55-59, 60-64, 65-69, 70-74, 75-79, 80-84, 85+). Причем для каждой группы было выделено число неработающих как разницы между численностью группы и числом работающих. Представленные данные показывают, что в возрастной группе 70-74 численность работающих становится статистической погрешностью:

1. Прямая аппроксимация статистических данных (рис. 4) средствами EXCEL.

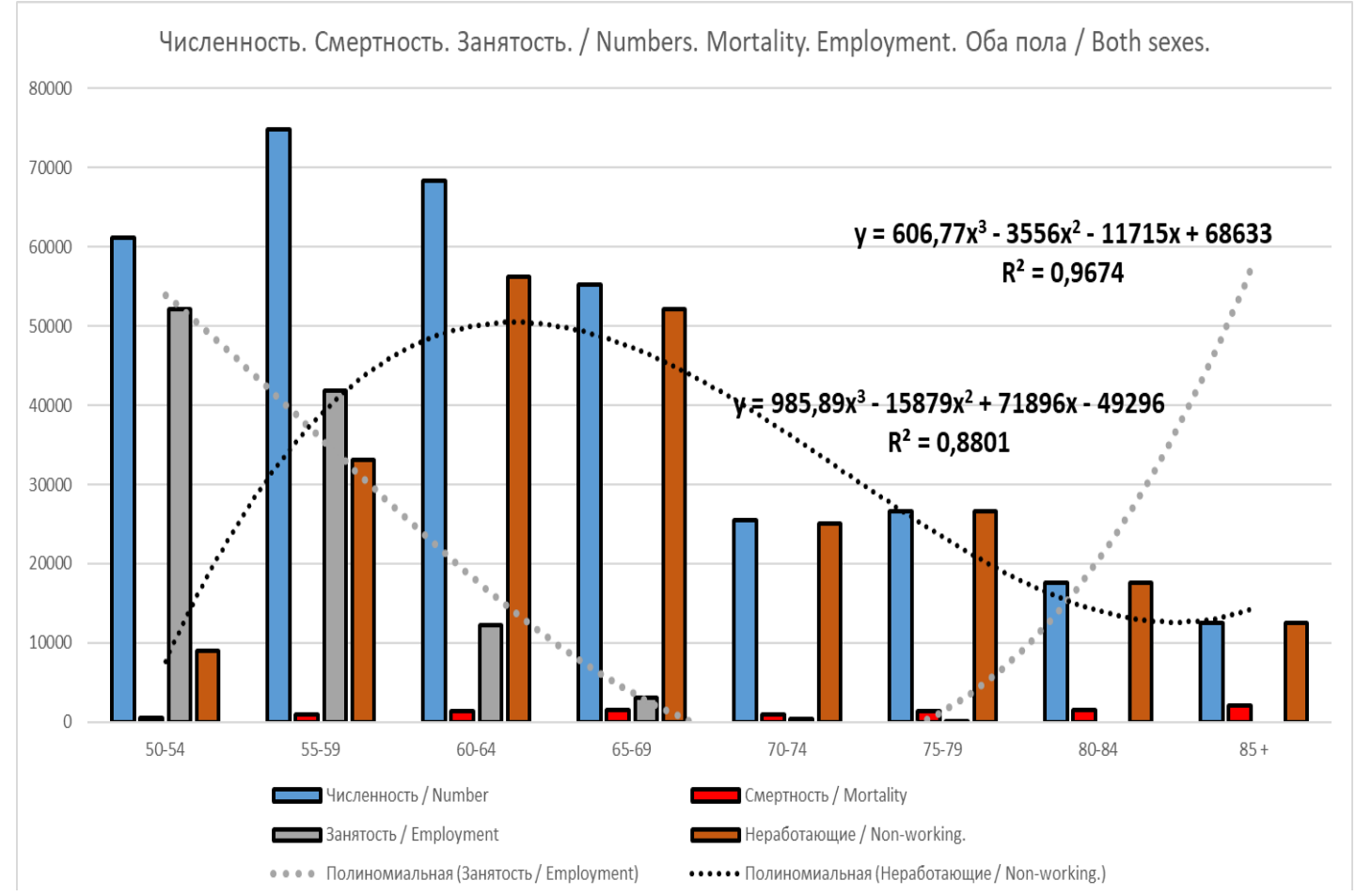

Puс. 4. Прямая аппроксимация статистических данных

для старших возрастных групп

Fig. 4. Direct approximation of statistical data for older age groups 
2. Но данные прямой аппроксимации (рис. 4) плохо поддаются и качественной, и количественной интерпретации. Поэтому была проведена нормировка данных занятости и смертности на численность каждой возрастной группы. Такое представление статистических данных позволило выделить три основных процесса, определяющих реализацию потенциала старшего поколения: процесс участия в трудовой силе; процесс выхода из трудовой деятельности; процесс смертности в каждой возрастной группе (рис. 5-7). Замечание: процесс выхода из трудовой деятельности фиксирует факт возможности реализации потенциала этой части людей старшего возраста только в социальной сфере.

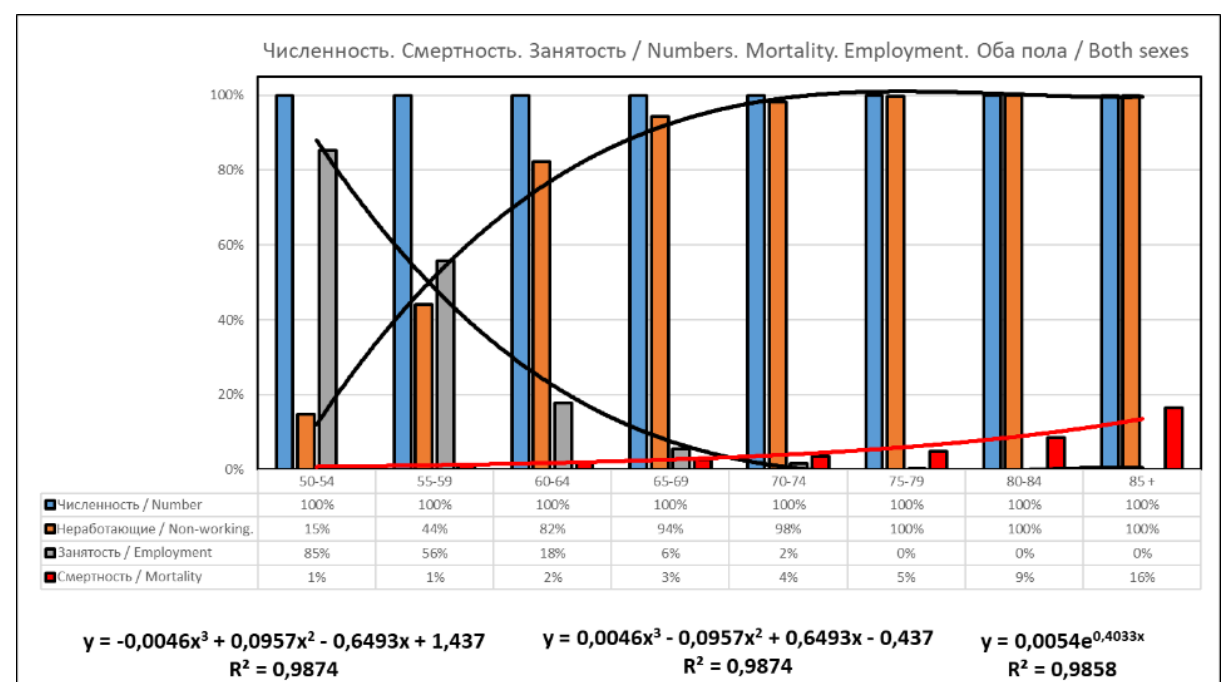

Рис. 5. Основные процессы, определяющие реализацию потенциала старшего поколения. Оба пола

Fig. 5. Key processes guiding the realization of the potential of the older generation. Both sexes

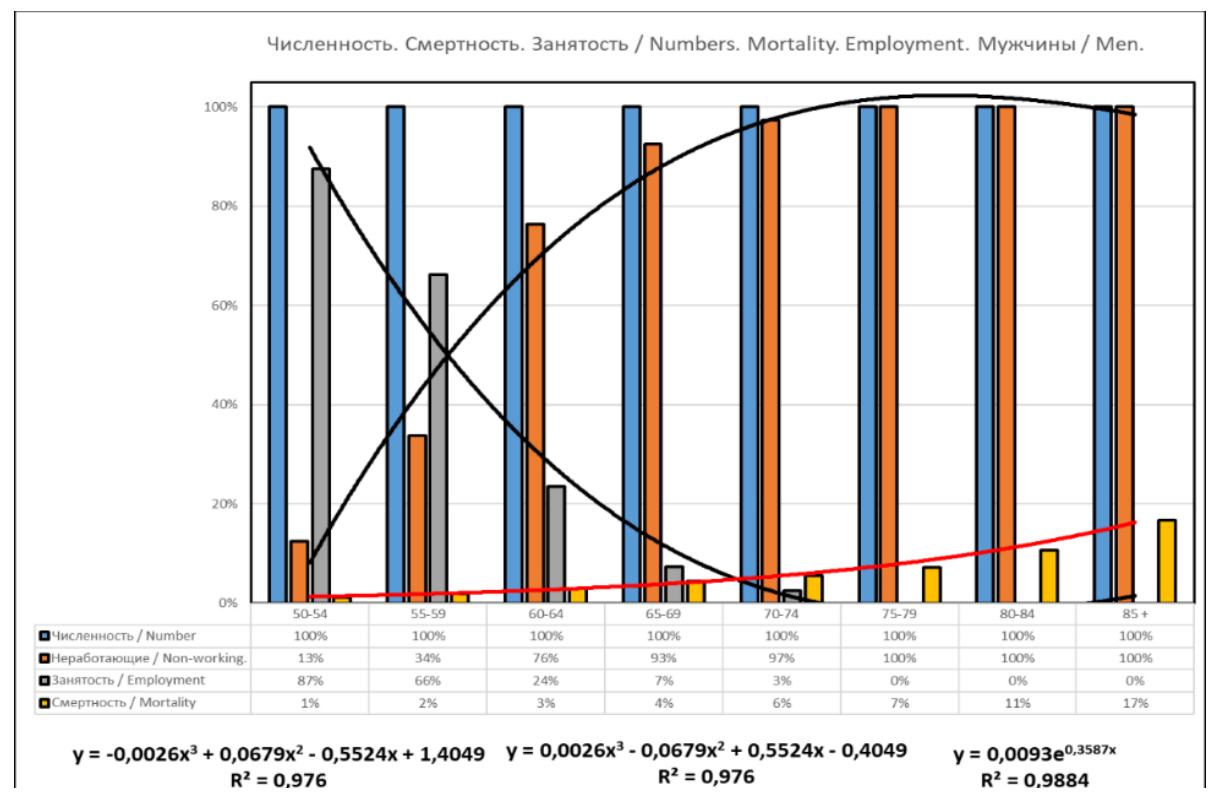

Рис. 6. Основные процессы, определяющие реализацию потенциала старшего поколения. Мужчины

Fig. 6. Key processes guiding the realization of the potential of the older generation. Men 


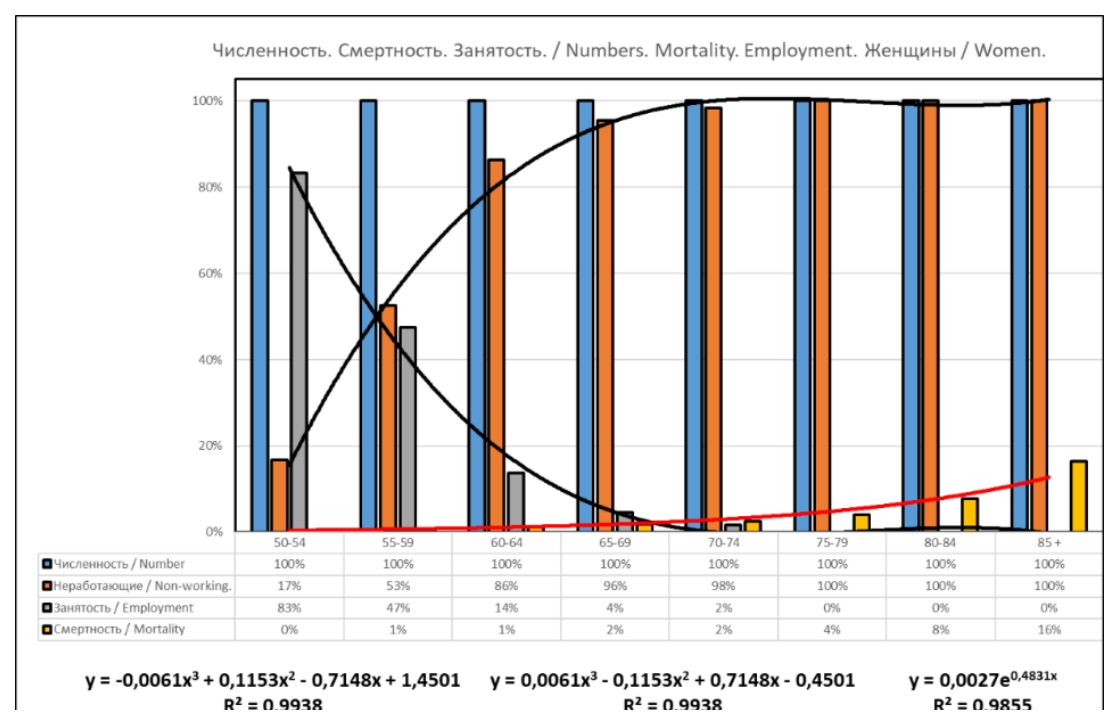

Рис. 7. Основные процессы, определяющие реализацию потенциала старшего поколения. Женщины

Fig. 7. Key processes guiding the realization of the potential of the older generation. Women

3. Проведенная работа позволила провести сравнение трех важнейших процессов жизнедеятельности человека: процесс участия в трудовой силе; процесс выхода из трудовой деятельности; процесс смертности в каждой возрастной группе. Для каждого из этих процессов проведена полиномиальная аппроксимация. Но процессов, влияющих на реализацию потенциала старшего поколения, значительно больше. Тем более, что эти процессы значительно сложнее чем выделенные процессы, отражаемые в статистической информации в явном виде. Была разработана модель-видение явления, включающая более широкие, чем было указано выше, процессы, влияющие на реализацию потенциала старшего поколения: социальный, экономический, физиологический, а также процессы формализованной и неформализованной поддержки старшего поколения (рис. 8).

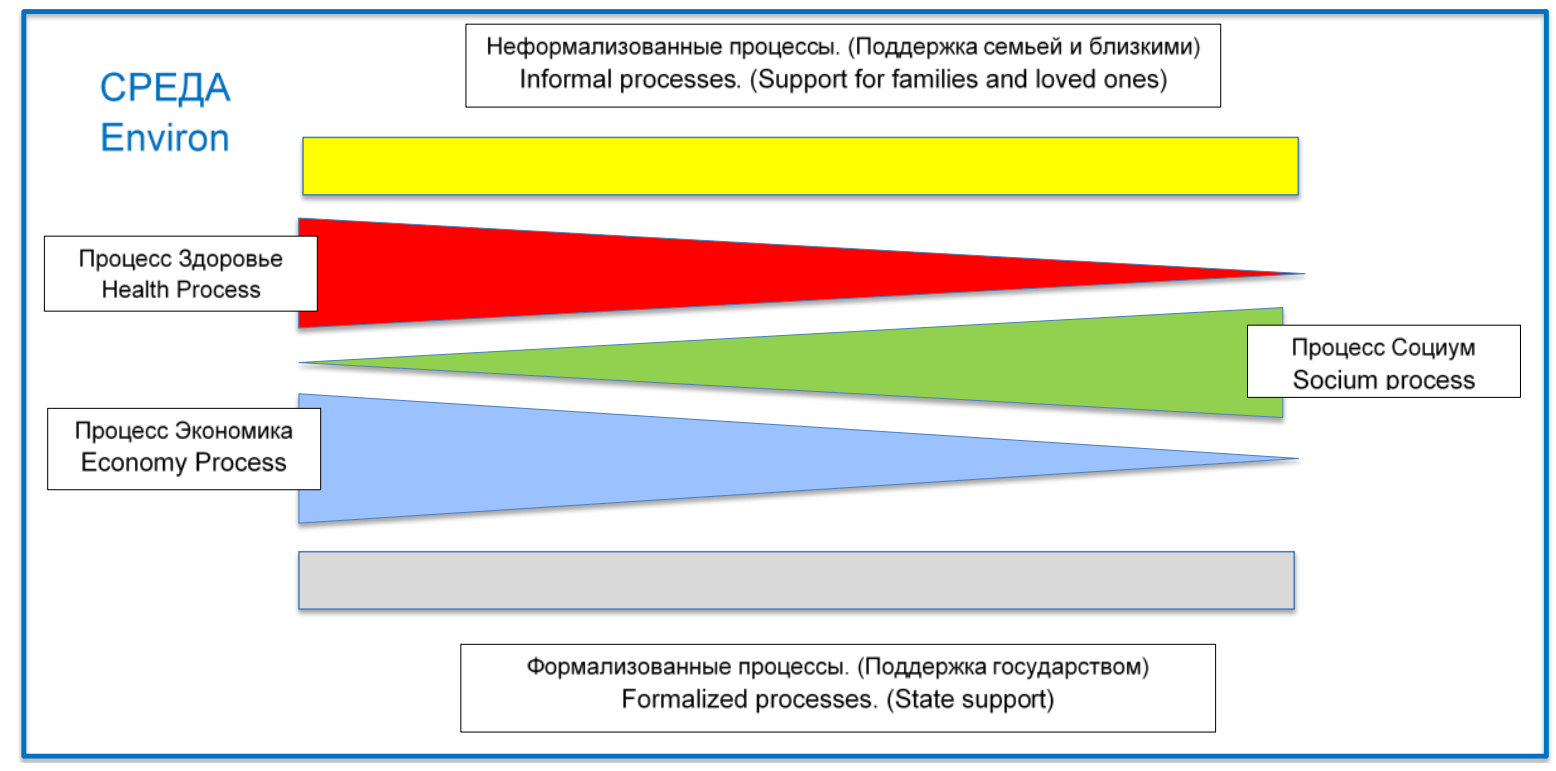

Рис. 8. Модель-видение явления «реализация потенциала старшего поколения» Fig. 8. Model-vision of the phenomenon «realization of the potential of the older generation» 
Процессы, представленные на рис. 8, являются институциональными процессами самого высокого уровня обобщения.

Процесс «Здоровье» характеризуется следующими параметрами: физическое состояние, наличие хронических заболеваний, смертность и т. п.

Процесс «Экономика» характеризуется следующими параметрами: труд по найму, самозанятость, участие в работе домохозяйств и т. п.

Процесс «Социум» характеризуется следующими параметрами: увлечения, общественная работа, политическая деятельность и т. п.

Формализованные процессы характеризуется следующими параметрами: пенсионное обеспечение, социальное обеспечение, система здравоохранения и т. п.

Неформализованные процессы характеризуется следующими параметрами: поддержка детьми, взаимодействие с родственниками, поддержка друзьями и т. п.

Среда. К ней отнесены прочие процессы, формирующие окружение людей старшего поколения: экология, городская среда, благоприятная для жизни, доступность магазинов, аптек, поликлиник и т. п.

Исследование выполнено при поддержке РНФ, проект № 19-18-00300 «Институты реализаиии ресурсного потенциила старшего поколения в экономике старения».

\section{СПИСОК ЛИТЕРАТУРЫ}

1. Реализация потенциала старшего поколения. Демографически процессы / Е.А. Монастырный, С.В. Касинский, Н.П. Дырко, В.В. Котова // Векторы благополучия: экономика и социум - 2019. № 3 (34) - C. 91-103. URL: http://jwt.su/journal/article/view/992/994 (дата обращения 21.01.2020).

2. Реализация потенциала старшего поколения. Уровень жизни / С.В. Касинский, Н.П. Дырко, В.В. Котова, И.А. Павлова, И.В. Гуменников, Е.А. Монастырный // Векторы благополучия: экономика и социум. - 2020. - № 1 (36). - С. 111-120. URL: http://jwt.su/journal/article/view/997/1033 (дата обращения 20.04.2020).

3. Рабочая сила, занятость и безработица в России (по результатам выборочных обследований рабочей силы): статистический сборник. - М.: Росстат, 2018. - 42 c. URL: https://www.gks.ru/free_doc/ doc_2018/rab_sila18.pdf (дата обращения 21.02.2020).

4. Старшее поколение // Федеральная служба государственной статистики. URL: https://www.gks.ru/ folder/13877 (дата обращения 21.02.2020).

5. Комплексное наблюдение условий жизни населения // Федеральная служба государственной статистики. URL: https://www.gks.ru/free_doc/new_site/KOUZ18/index.html (дата обращения 21.02.2020).

6. Российский мониторинг экономического положения и здоровья населения НИУ BШЭ. URL: https://www.hse.ru/rlms/ (дата обращения 21.02.2020).

7. Старения больше не будет / И.А. Григорьева, И.Л. Сизова, Л.А. Видясова, А.В. Дмитриева, О.А. Парфенова, И.С. Петухова. - СПб.: Астерион, 2018. - 136 с.

8. OECD Labour Force Statistics 2019. - Paris: OECD Publishing. URL: https://read.oecdilibrary.org/employment/oecd-labour-force-statistics-2019_g2g9fb3e-en\#page1 (дата обращения 21.02.2020).

9. Labour force statistics. 1978-1998. - OECD, 2000. - 368 p. URL: https://doi.org/10.1787/lfs-1999-en-fr (дата обращения 21.02.2020).

10. Palomba R., Kotowska I. The economically active population in Europe. URL: https://pdfs.semanticscholar.org/b8ed/050abc168f21955f0456e945956d802e5e64.pdf?_ga=2.120880718.71 1946101.1594897299-1551414766.1594897299 (дата обращения 21.02.2020).

11. Акофф Р. Планирование будущего корпорации. - М.: Прогресс, 1985. - 327 с.

12. Клейнер Г.Б. «Мягкие» и «жесткие» системы в экономике // XVII Международная конференция по мягким вычислениям и измерениям. Круглый стол «Экономическая кибернетика и мягкие системная экономика». - СПб.: СПбГЭТУ «ЛЭТИ», 2014. - С. 6-12.

13. Зуб А.Т., Локтионов М.В. Стратегический менеджмент: Системный подход. - М.: Генезис, 2011. $848 \mathrm{c}$. 
14. Гуменников И.В., Монастырный Е.А. Комплексное моделирование социально-экономических процессов и систем. Мягкий системный анализ // Информационные технологии в науке, управлении, социальной сфере и медицине: сборник научных трудов V Международной научной конференции. Часть 2. - Томск: Изд-во ТПУ, 2018. - С. 437-443.

15. Федеральная служба государственной статистики России. URL: https://www.gks.ru/ (дата обращения 21.02.2020).

16. Единая межведомственная информационно-статистическая система. URL: https://fedstat.ru/ (дата обращения 21.02.2020).

17. Территориальный орган Федеральной службы государственной статистики по Томской области. URL: https://tmsk.gks.ru/ (дата обращения 21.02.2020).

18. Старшее поколение Томской области. 2015: Аналитическая записка. - Томск: Томскстат, 2015 - 14 с.

19. Старшее поколение Томской области. 2016: Аналитическая записка. - Томск: Томскстат, 2016. $14 \mathrm{c}$.

20. Старшее поколение Томской области: демография и участие на рынке труда: Аналитическая записка. Томск: Томскстат, 2019 - $18 \mathrm{c}$.

21. Социально-экономическая статистика благополучия старшего поколения / Ф. Касати, Г.А. Барышева, Е.А. Монастырный, Л.И. Иванкина, И.А. Павлова, М.Л. Шинкеев, В.В. Спицын, Н.М. Панькова, И.В. Гуменников. - Томск: Интегральный переплет, 2016. - 264 с.

Поступила 25.04.2020 2. 
UDC 331.538:316.32-053.9

\title{
REALIZATION OF THE POTENTIAL OF THE OLDER GENERATION. PARTICIPATION IN THE LABOR MARKET
}

\author{
Eugeniy A. Monastyrny1,2,3, \\ e.monastyrny@gmail.com \\ Sergey V. Kasinsky", \\ P70_mail@gks.ru \\ Nina P. Dyrko4, \\ P70_mail@gks.ru \\ Valentina V. Kotova ${ }^{4}$, \\ P70_mail@gks.ru \\ Irina A. Pavlova $a^{3,2,1}$, \\ iapav@mail.ru \\ 1 National Research Tomsk Polytechnic University, \\ 30, Lenin avenue, Tomsk, 634050, Russia. \\ 2 Tomsk State University of Control Systems and Radioelectronics, \\ 40, Lenin avenue Tomsk, 634050, Russia. \\ 3 Tomsk Scientific Center SB RAS, \\ 10/4, Academichesky avenue, Tomsk, 634055, Russia. \\ ${ }^{4}$ Territorial Body of the Federal Service for State Statistics for the Tomsk Region, \\ 56, Gagarin street, Tomsk, 634050, Russia.
}

Eugeniy A. Monastyrny, Dr. Sc., professor, National Research Tomsk Polytechnic University,; professor, Tomsk State University of Control Systems and Radioelectronics; head of the laboratory of sustainability of socio-economic systems, Tomsk Scientific Center SB RAS.

Sergey V. Kasinsky, head of the Territorial Body of the Federal Service for State Statistics for the Tomsk Region.

Nina P. Dyrko, deputy head of the Territorial Body of the Federal Service for State Statistics for the Tomsk Region.

Valentina V. Kotova, chief specialist, Territorial Body of the Federal Service for State Statistics for the Tomsk Region.

Irina A. Pavlova, Cand. Sc., senior researcher, Tomsk Scientific Center SB RAS (TSC SB RAS); associate professor, National Research Tomsk Polytechnic University; associate professor, Tomsk State University of Control Systems and Radioelectronics (TUSUR).

The relevance of the work is determined by global processes: (1) ageing of the population as a whole, caused by declining fertility and rising longevity; (2) increase in the economically active age. Labor force statistics in the Russian Federation is traditionally considered as statistics of persons of working age and persons over the working age. Details of older age groups are usually limited. This is observed both in specialized official statistical collections and in the section «Older generation» of the Federal State Statistics Service. Moreover, for many indicators of federal statistics there is no free access in the regional context. The purpose of the present study is defined in the first article of the cycle and remains the same - to evaluate the characteristics of 
the sample of senior age groups and old-age pensioners according to the statistical data of Rosstat and the Pension Fund of the Russian Federation for the Tomsk region from the point of view of information preparation for making managerial decisions. The objectives of this work are to study the participation of older people in the labor force and to develop models for realization of the labor potential of older people. The sources of information are Rosstat, the Unified Interdepartmental Information and Statistical Systems (EMISS), Tomskstat, information obtained upon agreed requests to the territorial statistical office, and the results of sociological research. Methodology. The authors have used the following approaches of descriptive statistics: comparisons, relations, visualization of dynamics of changes, statistical analysis. The logic, structure and methods of analysis of the material correspond to those adopted in official statistical surveys and policy briefs. "Soft" system analysis approaches are used in modeling. Results. The article provides a detailed analysis of the situation of pensioners in the labor market, the distribution of the employed population of different age groups by types of economic activity, occupation (positions) and age groups. Based on the results of the analysis of statistical data, the conclusions were drawn. In the Tomsk region in the period from 2010 to 2018 the trend of demographic aging of the population was traced. One of the consequences of the increase in the share of elderly people is the increase in the demographic burden on the able-bodied population of working age. This leads to the need to expand the labor market, mainly the employment of pensioners. Modeling. The selected presentation of statistical data has made it possible to identify three main processes that determine the realization of the potential of the older generation: (1) participation in labor force, (2) exit from labor force, and (3) mortality in each age group. The data show that in the age group 70-74 the number of employees becomes a statistical error, and the process of exit from labor force records the fact that it is possible to realize the potential of this part of older people only in the social sphere. The polynomial approximation was carried out for the selected processes. A model-vision of the phenomenon was developed, which includes broader processes affecting the realization of the potential of the older generation: social, economic, physiological, as well as the processes of formalized and informalized support of the older generation.

Key words: Realization of labour potential, working pensioners, senior age groups, reform of the pension system.

The research was carried out with the support of the Russian National Research Foundation, project no. 19-18-00300 "Institutes of realization of resource potential of the older generation in the economy of aging».

\section{REFERENCES}

1. Monastyrny E.A., Kasinsky S.V., Dyrko N.P. Kotova V.V. Realization of the potential of the older generation. Demographic processes. Journal of Wellbeing Technologies, 2019, no. 3 (34), pp. 91-103. In Rus. Available at: http://jwt.su/journal/article/view/992/994 (accessed 21.01.2020).

2. Kasinsky S.V., Dyrko N.P. Kotova V.V., Pavlova I.A., Gumennikov I.V., Monastyrny E.A. Realization of the potential of the older generation. Standard of living. Journal of Wellbeing Technologies, 2020, no. 1 (36), pp. 111-120. In Rus. Available at: http://jwt.su/journal/article/view/997/1033 (accessed 20.04.2020).

3. Rabochaya sila, zanyatost i bezrabotitsa v Rossii (po rezultatam vyborochnykh obsledovaniy rabochey sily). Statisticheskiy sbornik [Labor force, employment and unemployment in Russia (based on the results of sample labor force surveys). Statistical collection]. Moscow, Rosstat Publ., 2018. 42 p. Available at: https://www.gks.ru/free_doc/doc_2018/rab_sila18.pdf (accessed 21 February 2020).

4. Starshee pokolenie [Older generation]. Federalnaya sluzhba gosudarstvennoy statistiki [Federal State Statistics Service]. Available at: https://www.gks.ru/folder/13877 (accessed 21 Februry 2020).

5. Kompleksnoe nablyudenie usloviy zhizni naseleniya [Comprehensive observation of living conditions of the population]. Federalnaya sluzhba gosudarstvennoy statistiki [Federal State Statistics Service]. Available at: https://www.gks.ru/free_doc/new_site/KOUZ18/index.html (accessed 21 February 2020).

6. Rossiyskiy monitoring ekonomicheskogo polozheniya i zdorovya naseleniya [Russian monitoring of the economic situation and health of the population]. National Research University Higher School of Economics. Available at: https://www.hse.ru/rlms/ (accessed 21 February 2020).

7. Grigoryeva I.A., Sizova I.L., Vidyasova L.A., Dmitriyeva A.V., Parfenova O.A., Petukhova I.S. Stareniya bolshe ne budet [There will be no more aging]. St. Petersburg, Asterion Publ., 2018. 136 p.

8. OECD Labour Force Statistics 2019. Paris, OECD Publishing. Available at: https://read.oecdilibrary.org/employment/oecd-labour-force-statistics-2019_g2g9fb3e-en\#page1 (accessed 21 February 2020). 
9. Labour force statistics. 1978-1998. OECD, 2000, 368 p. Available at: https://doi.org/10.1787/lfs-1999-en-fr (accessed 21 February 2020).

10. Palomba R., Kotowska I. The economically active population in Europe. Available at: https://pdfs.semanticscholar.org/b8ed/050abc168f21955f0456e945956d802e5e64.pdf?_ga=2.120880718.71 1946101.1594897299-1551414766.1594897299 (accessed 21 February 2020).

11. Akoff R. Planirovanie budushchego korporatsii [Planning the future of the corporation]. Moscow, Progress Publ., 1985. 327 p.

12. Kleyner G.B. «Myagkie» i «zhestkie» sistemy v ekonomike [«Soft» and «hard» systems in economics]. XVII Mezhdunarodnaya konferentsiya po myagkim vychisleniyam i izmereniyam. Krugly stol «Ekonomicheskaya kibernetika i myagkaya sistemnaya ekonomika» [XVII International Conference on Soft Computing and Measurements. Round table «Economic cybernetics and soft systems economy»]. St. Petersburg, SPbGETU «LETI» Publ., 2014. pp. 6-12.

13. Zub A.T., Loktionov M.V. Strategicheskiy menedzhment: sistemny podkhod [Strategic management: a systematic approach]. Moscow, Genezis Publ., 2011. 848 p.

14. Gumennikov I.V., Monastyrny E.A. Kompleksnoe modelirovanie sotsialno-ekonomicheskikh protsessov i sistem. Myagkiy sistemny analiz [Integrated modeling of socio-economic processes and systems. Soft system analysis]. Informatsionnye tekhnologii $v$ nauke, upravlenii, sotsialnoy sfere $i$ meditsine: sbornik nauchnykh trudov V Mezhdunarodnoy nauchnoy konferentsii. Chast 2 [Information technologies in science, management, social sphere and medicine: collection of scientific papers of the $\mathrm{V}$ International scientific conference. Part 2]. Tomsk, TPU Publ., 2018. pp. 437-443.

15. Federalnaya sluzhba gosudarstvennoy statistiki Rossii [Federal State Statistics Service of Russia]. Available at: https://www.gks.ru/ (accessed 21 February 2020).

16. Edinaya mezhvedomstvennaya informatsionno-statisticheskaya sistema [Unified interdepartmental information and statistical system]. Available at: https://fedstat.ru/ (accessed 21 February 2020).

17. Territorialny organ Federalnoy sluzhby gosudarstvennoy statistiki po Tomskoy oblasti [Territorial body of the Federal State Statistics Service in the Tomsk Region]. Available at: https://tmsk.gks.ru/ (accessed 21 February 2020).

18. Starshee pokolenie Tomskoy oblasti. 2015: Analiticheskaya zapiska [The older generation of the Tomsk region. 2015: Analytical note]. Tomsk, Tomskstat Publ., 2015. 14 p.

19. Starshee pokolenie Tomskoy oblasti. 2016: Analiticheskaya zapiska [The older generation of the Tomsk region. 2016: Analytical note]. Tomsk, Tomskstat Publ., 2016. 14 p.

20. Starshee pokolenie Tomskoy oblasti: demografiya i uchastie na rynke truda: Analiticheskaya zapiska [The older generation of the Tomsk region: demography and participation in the labor market: Analytical note]. Tomsk, Tomskstat Publ., 2019. 18 p.

21. Kasati F., Barysheva G.A., Monastyrny E.A., Ivankina L.I., Pavlova I.A., Shinkeev M.L., Spitsyn V.V., Pankova N.M., Gumennikov I.V. Sotsialno-ekonomicheskaya statistika blagopoluchiya starshego pokoleniya [Socio-economic statistics of well-being of the older generation]. Tomsk, Integralny pereplet Publ., 2016. 264 p.

Received: 25 April 2020. 